\title{
The soul of the machine: continual improvement in ISO 14001
}

\author{
Martin A.C. Brouwer, C.S.A. (Kris) van Koppen* \\ Wageningen University, Social Sciences Group, Hollandseweg 1, 6706 KN Wageningen, The Netherlands
}

Received 23 August 2006; accepted 23 August 2006

Available online 27 October 2006

\begin{abstract}
Continual improvement is a key component of ISO 14001, but in contrast to most other specifications in the standard, it is difficult to assess. Based on interviews with 19 certified companies in the chemical, food, and environmental services sectors, this article explores the dynamics of continual improvement. While most auditing practices focus on the operational level of improvement, the system level is more important in realizing continual improvement. Taking continual improvement as an explicit principle, defining long-term objectives, and widening the scope of environmental policy objectives can be used as indicators for system level improvement. Front-runners in continual improvement tend to use more management indicators and think more favourably on benchmarking. They are relatively stronger motivated by internal policy ambitions, and parent company aims than by pressures from outside. Further elaboration of performance frameworks for continual improvement is needed, taking into account the way performance indicators can stimulate internal motivational, and policy processes.
\end{abstract}

(C) 2006 Elsevier Ltd. All rights reserved.

Keywords: Continual improvement; ISO 14001; Measuring environmental performance

\section{Introduction}

Since it was formally issued in 1996 , more than 87,000 organizations in 128 countries have been certified against the ISO 14001 Environmental Management System Standard (Peglau Liste 2005 [17]). Probably, this number will further increase in the years to come. The standard has become a household name among business and governmental organizations around the world. In addition to a vast number of handbooks and brochures for implementing and auditing the standard, several studies have been published which review and evaluate the standard from a more scientific point of view.

The results of these studies are not as bright as the perspectives usually pictured in brochures and on internet sites. Criticism has been levelled against the standard's emphasis on management procedures, rather than actual improvements in environmental performance (e.g. [2]), on its dependence on

\footnotetext{
* Corresponding author. Tel.: +31 317 482617/4452; fax: +31 317483990 .

E-mail address: kris.vankoppen@wur.nl (C.S.A.(Kris) van Koppen).
}

the quality of national environmental regulations for setting minimum pollution requirements and on the standard's tendency of becoming a market instrument rather than an environmental quality improvement tool, among others (e.g. [13]).

Notwithstanding such criticism, the balance of nearly a decade of ISO 14001 implementation is definitely positive as long as the focus is on individual organizations that enter the certification scheme.

In most cases, the environmental performance of these organizations improves in the process of certification, as they are induced to systematically review and document significant environmental aspects and have to meet the baseline of compliance to existing regulations [1].

But what is the impact of ISO 14001 once the certificate has been obtained and the organization basically complies to regulatory requirements? Doubts have been raised whether ISO 14001 can give an impetus to preventive waste- and emission reduction [8], and whether it fosters a culture of innovative environmental care [15]. These questions - bound to become more central the longer ISO 14001 is around - boil down to the issue of continual improvement. 
Continual improvement is a key element of ISO 14001. It is at the heart of the Plan-Do-Check-Act (PDCA) cycle that is the engine of the environmental management system. Together with compliance and pollution prevention, it is a basic commitment the organization has to endorse in its environmental policy and in its environmental practice. But, in contrast to the specification of other elements in ISO 14001, the standard lacks an operational definition of what continual improvement is and how it should be assessed.

Several publications have exposed this under determination of continual improvement in ISO 14001 [1,21]. As research demonstrates, the principle leaves room for widely diverging company strategies. While some companies are actually realizing continual environmental improvement, for others it seems possible even to move in the opposite direction, without losing their certificate $[1,14,18]$.

Based on a thesis research project at Wageningen University [3], this article sets out to analyze the dynamics of continual improvement in companies certified against ISO 14001. Which internal and external factors influence the process of continual improvement in these companies? How do companies and auditors assess continual improvement? In what ways does the ISO 14001 standard provide an incentive for continual improvement?

To answer these questions, in-depth interviews were held with 19 Dutch certified companies, divided over three sectors: chemical industries, food industries, and the environmental services sector. The chemical sector was selected because it is one of the most important industrial sectors in terms of environmental impacts, and has an extensive record in dealing with environmental management issues. The food industries were selected because they constitute a major Dutch industrial sector, with a broad range of environmental aspects, but in comparison with chemical industries, far less acute problems, public exposure, and management experience in dealing with environment. The environmental services sector was included as we were interested in the performance of service sector companies; by taking environmental services companies, we made sure that the companies investigated, in any case, were aware of environmental management issues. The interviews were held in 2004.

Within these sectors, companies were selected at random. The sample of interviewed companies includes, AKZO Nobel, DuPont, Shell, BP, Heinz, CSM, Grolsch, Yakult, Swedish Match, VAR, Sita and Heijmans. In addition, four certifying bodies, also selected at random, were interviewed: Lloyd's, KEMA, Det Norske Veritas and SGS ICS.

Before presenting the outcomes of the research, key characteristics of continual improvement in ISO 14001 are identified in the next section.

\section{Continual improvement in ISO 14001}

\subsection{Definition of continual improvement}

ISO 14001 defines continual improvement as "a process of enhancing the environmental management system in order to achieve improvements in overall environmental performance consistent with the organization's environmental policy" [9].

The description makes clear that improvements in environmental performance are the ultimate touchstone for continual improvement. Moreover, the description suggests that such improvements are based on enhancement of the environmental management system itself. Two major aspects of continual improvement are implied in this definition. One is how to identify and quantify - or, how to measure - improvement of environmental performance. The other is how to embed continual improvement in the structure of the environmental management system. Both aspects are briefly reviewed in this section.

\subsection{Measuring environmental performance}

"If you don't measure it, you can't manage it", has become catch phrase within the discipline of environmental management. There is an increasing interest in indicators for measuring environmental performance [16]. Company-specific environmental indicator systems are an important tool in planning, steering and controlling environmental performance. Comparing indicators from year to year, and between sites or companies (benchmarking), allows for an evaluation of the relative environmental progress of a company [11].

Measuring environmental performance is elaborated in the ISO 14031 standard, which is a guidance standard in the ISO 14000 Series of Standards. This standard offers a description of environmental performance evaluation in terms of definitions and management structure (plan-do-check-act), and an indicator typology. The typology distinguishes between environmental condition indicators (ECIs), process or operational performance indicators (OPIs), and management performance indicators (MPIs) $[10,16]$.

Several other - voluntary - international frameworks have been developed for measuring and comparing environmental performance of companies. Some well-known examples are listed here [5,20]:

- Global Reporting Initiative (GRI): guidelines for sustainable reporting. Used for reporting on economic, environmental, and social dimensions of activities, products, and services.

- Social Accountability (SA 8000): based on workplace norms. Addresses eight categories of indicators, from human rights oriented to specific environmental categories of indicators.

- World Business Council for Sustainable Development (WBCSD): a coalition of 170 international companies united by a shared commitment to sustainable development. Addresses three pillars: economic growth, ecological balance, and social progress.

- The European environmental framework of the European Environmental Agency (EEA): 32 environmental indicators to measure, communicate, and analyze sustainable development. 
- EMAS (since 2001, EMAS II): addresses three categories of environmental performance indicators: "operational performance indicators, management performance indicators, and environmental condition indicators".

Each framework has its specific characteristics, but there is also considerable overlap. All frameworks adhere to the distinction between output or process indicators, and management indicators. Table 1 gives an overview of environmental indicators that are considered relevant by a majority $(\geq 5)$ of the listed frameworks.

ISO 14001 obliges companies to formulate targets in terms of measurable performance in accordance to the environmental objectives, and to record their progress toward these targets. A basic notion of continual improvement, therefore, is that a company can show progress toward meeting its environmental objectives, with the help of adequate or "SMART" - that means specific, measurable, attainable, result-oriented, and time bound - performance indicators.

\subsection{Structuring environmental improvement}

For a better understanding of the dynamics of continual improvement, it is important to look at the way objectives and targets are embedded in the structure of the management system. For this purpose, a tactical (short-term), and a strategic (long-term) improvement cycle can be distinguished (see Fig. 1).

The tactical cycle centres around achieving established objectives and targets. Continual improvement in this cycle means moving toward the targets. These targets, based on existing environmental objectives, constitute a clear point of reference for improvement in the tactical cycle, and continual improvement can be measured by means of a proper set of indicators. In other words, the basic notion of continual improvement, as outlined in the previous section, pertains to this tactical cycle.

Table 1

Common environmental indicators in international performance indicator frameworks

\begin{tabular}{ll}
\hline Output/process indicators & - Energy use (specified to kind of energy, e.g. \\
fossil fuels, renewable energy, recycled energy) \\
- Material use (specified to kind of material) \\
- Specific emissions to the air (such as $\mathrm{CO}_{2}$, \\
$\mathrm{NO}_{x}, \mathrm{SO}_{2},(\mathrm{H}) \mathrm{CFCs}, \mathrm{VOC}$ ) \\
- Amount of emitted wastewater \\
- Amount and composition of waste (domestic, \\
- industrial, dangerous) \\
- Recollection (withdraw) of waste \\
- Total environmental costs \\
- Total environmental \\
investments (in eco-technologies) \\
- Amount of and/or investment in environmental \\
education \\
- Number of incidents and accidents \\
- Number of complaints \\
- Number of environmental ideas of personnel
\end{tabular}

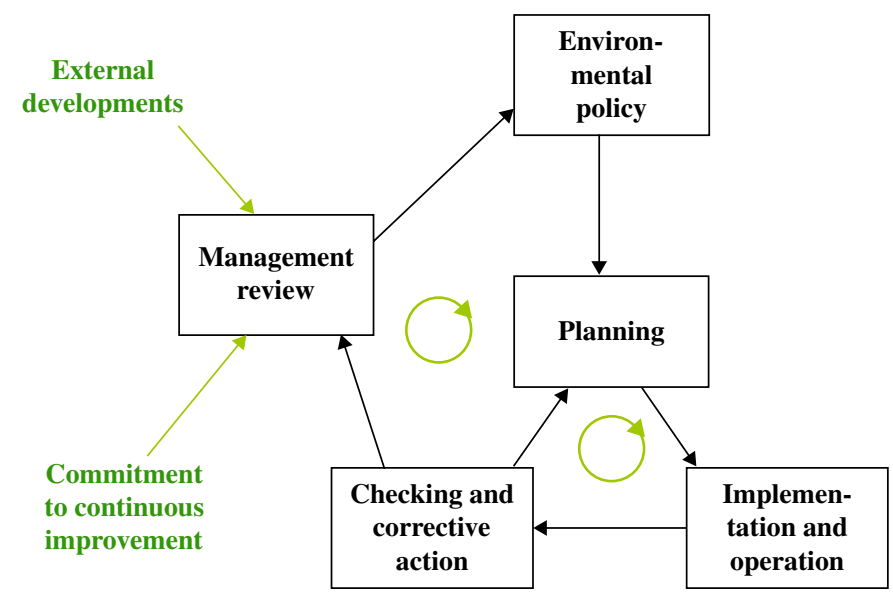

Fig. 1. Two improvement cycles in ISO 14001 (translated from Heida and Hortensius [6]).

It is also clear, however, that improvement in the tactical cycle is insufficient as a determinant of continual improvement. The overall environmental progress of a company will strongly depend on the ambition level of the objectives [4]. A company which is slowly progressing toward high ambition objectives may actually perform much better than one that is more rapidly moving toward very modest objectives. The level and scope of the objectives is set in the strategic cycle, which consists of continual adjustment of the objectives of the companies environmental policy, under influence of both external developments and internal motivation. Finding references for improvement in the strategic cycle is much more complex than measuring tactical improvement. Without any pretensions to being complete, we will describe four possible references for strategic improvement: having continual improvement as general principle, setting long-term technological or emission standards, having a range of objectives beyond process control, and having a system for assessing continual improvement. Companies often formulate general normative principles, such as sustainability, environmental safety and health, or eco-efficiency, as foundation of their environmental policy. Unlike environmental targets, environmental principles usually cannot be quantified [7].

When taken seriously, however, they are highly relevant to strategic improvement and may be regarded as long-term aims of a company.

Continual improvement is such a principle in itself. Many companies explicitly express their ambition of realizing continual improvement in environmental performance. An explicitly stated ambition to continually improve can be taken as a positive indicator of strategic improvement.

Another approach to strategic improvement is that of longterm objectives. By setting long-term objectives, aims can be set that require more fundamental changes over a period of many years. Long-term objectives should then be translated into short-term objectives and be reviewed periodically [19]. ISO 14001 does not provide a clear point of reference for the establishment of ambitious long-term objectives. For 
EMAS, the principle of Economically Viable Application of Best Available Technologies (EVABAT) is mentioned as a reference for continual improvement [6], but this is not the case for ISO 14001. Moreover, neither EMAS nor ISO 14001 do by any means hinder companies to go beyond the level of EVABAT [7].

In the EU directive for Integrated Prevention and Pollution Control (IPPC), Best Available Technology (BAT) is elaborated as standard for specific categories of companies. Since the IPPC directive sets BAT as compliance requirement, it is unclear to what extent it can serve as a long-term objective for continual improvement.

Another way of approaching long-term objectives is to look how wide the range of objectives is, and more in particular, to inventory the objectives that go beyond prevention and pollution control for on-site production processes. Wider objectives include, for example, use of life cycle assessment (LCA), application of industrial ecology principles, or product stewardship. This emphasis on the widening of environmental objectives is in line with development models of environmental management, which postulate that environmentally advanced companies tend to shift focus from the performance of the plant to the performance of the chain (e.g. [12]).

Due to the complex nature of continual improvement, there are, as yet, no generally accepted methods for assessing continual improvement, neither among companies, nor among certification bodies. Nonetheless, companies that have an explicit policy for continual improvement feel the need of making reliable assessments of their progress in this respect.

Therefore, many of them have developed their own specific methods for assessing continual improvement (see Table 4). The existence of such a specific assessment can in itself be considered a positive indicator of continual improvement as strategic objective.

In this research, having continual improvement as principle, having a range of objectives beyond process control, and having a specific system of assessing continual improvement are taken as indicators of strategic environmental improvement.

\section{Research results}

\subsection{Measuring and benchmarking continual improvement}

The companies were interviewed about the actual use of performance indicators and about their opinion on benchmarking of continual improvement. A majority of respondents, 12 of 19 companies, and three of four certification agencies, were negative about benchmarking continual improvement over different companies. "Continual improvement is an absolute measure and it is very difficult to express it as a measure relative to other companies" was the most frequently heard comment. Moreover, degrees of improvement are strongly dependent on specific internal company characteristics, such as organizational aspects, location and production process.

As Table 2 shows, most of the companies in our survey, 17 out of 19, use performance indicators. Operational or process-/
Table 2

Percentage of companies that are using the different categories of indicators

\begin{tabular}{llllll}
\hline & All three & OPIs \& MPIs & OPIs \& ECIs & Only OPIs & None \\
\hline Total & $4(21 \%)$ & $6(32 \%)$ & $1(5 \%)$ & $6(32 \%)$ & $2(10 \%)$
\end{tabular}

OPIs, operational performance indicators; MPIs, management performance indicators; ECIs, environmental condition indicators.

output performance indicators are applied by all companies using performance indicators. Only half of the companies use management or strategic performance indicators, even when this category of indicators appears to be particularly relevant for measuring continual improvement [20].

The companies in our sample hardly made use of the ISO 14031 standard for performance evaluation. Only one of the interviewed companies actually utilized this standard, while nine companies knew the existence of the standard, but did not use it, and nine had never heard of the ISO 14031 standard.

Investigated are the relationship between companies' use of indicators and their view on benchmarking. Table 3 shows the categories of indicator used by the companies that are positive about benchmarking, in comparison with the companies that responded negatively about benchmarking.

Clearly, companies with a more favourable view on benchmark apply indicators more, and make more use of other types of indicators than only operational performance indicators.

Most of the companies in favour of benchmarking, six out of seven are front-runners in continual improvement (see next section).

As there are no uniform standards available for assessing continual improvement, the companies investigated used different methods for this purpose. Not surprisingly, the kind of methods used is related to the company characteristics. Production companies use process and output indicators more often than service providers do. Table 4 shows general methods for assessing continual improvement that were reported by two or more companies.

\subsection{Front-runners and motivational factors}

To explore which motivational factors are contributing to continual improvement in companies, front-runners and other companies are compared in our sample. Based on the considerations outlined above, front-runners in continual

Table 3

Benchmarking and use of indicators

\begin{tabular}{lll}
\hline & $\begin{array}{l}\text { Companies positive } \\
\text { about benchmarking } \\
(n=7)\end{array}$ & $\begin{array}{l}\text { Companies not positive } \\
\text { about benchmarking } \\
(n=12)\end{array}$ \\
\hline All three categories & $2(29 \%)$ & $2(17 \%)$ \\
OPIs \& MPIs & $3(43 \%)$ & $3(25 \%)$ \\
OPIs \& ECIs & $1(14 \%)$ & - \\
Only OPIs & $1(14 \%)$ & $5(42 \%)$ \\
None & - & $2(17 \%)$ \\
\hline
\end{tabular}

OPIs, operational performance indicators; MPIs, management performance indicators; ECIs, environmental condition indicators. 
Table 4

General methods for assessing continual improvement

\begin{tabular}{ll}
\hline $\begin{array}{l}\text { Number of } \\
\text { companies }(\%)\end{array}$ & $\begin{array}{l}\text { General methods for measuring and assessing } \\
\text { continual improvement }\end{array}$ \\
\hline $7(37 \%)$ & $\begin{array}{l}\text { By using specific indicators. The indicators } \\
\text { are recorded, evaluated and documented. } \\
\text { Evaluation is done over several years. } \\
\text { By internal and external audits. The audit } \\
\text { results are recorded and documented. }\end{array}$ \\
$3(16 \%)$ & $\begin{array}{l}\text { By achievement and adjustment of objectives } \\
\text { and targets. Achievement has to be documented } \\
\text { in an annual report, and new, higher level } \\
\text { objectives and targets are developed. } \\
\text { By continually running the PDCA cycle } \\
\text { on each aspect, beginning at a very low and } \\
\text { concrete level, and moving up to higher } \\
\text { and more systemic levels. } \\
\text { By measurement and reporting of all relevant } \\
\text { emissions. } \\
\text { By so-called Six Sigma projects (a quality } \\
\text { system-based method for identifying problems } \\
\text { and reducing errors). }\end{array}$ \\
&
\end{tabular}

improvement are distinguished by constructing an aggregated score, based on three parameters:

(1) a stated ambition to realize continual improvement;

(2) the number of high-level long-term objectives beyond site performance; and

(3) the existence of a functioning system for assessing continual improvement.

Eight companies scored substantially higher than the others and were selected as front-runners. For several company characteristics, the scores of the front-runners in continual improvement are compared with the scores of the other companies.

\subsection{Reasons for adopting an EMS and ISO 14001 certification}

Companies were asked to indicate the relative importance of different reasons for adopting an Environmental Management System (EMS). They were also asked what made them certify against ISO 14001, and what turned out to be an important added value of ISO 14001 after certification. The answers were scored according to a 4-point scale (from $1=$ no importance, to $4=$ high importance). Table 5 presents the results. Clear differences exist between front-runners and other companies.

Motives such as cost reduction, better relations, and reduction of impacts are slightly more important among front-runners, but what they particularly value is a better grip on environmental policy. Pressure from government is less important as a reason for certification to the front-runners, and the impact of the parent company is significant. Front-runners see more added value of certifications in several respects. The internal impulse of certification, however, is most important to them.
Table 5

Importance to companies of motives for environmental care and certification (averages of company scores on a 4-point scale): comparison of front-runners and other companies

\begin{tabular}{lll}
\hline & 8 Front-runners & $\begin{array}{l}\text { Other 11 } \\
\text { companies }\end{array}$ \\
\hline Reasons for having an EMS & & \\
$\quad$ Reduction of environmental costs & 2.8 & 2.6 \\
Better relationship with stakeholders & 3.5 & 3.3 \\
Firmer grip on environmental policy & $3.3^{\mathrm{a}}$ & $2.6^{\mathrm{a}}$ \\
$\quad$ Reduction of environmental risks & 2.9 & 3.2 \\
$\quad$ Reduction of environmental impacts & 3.0 & 2.8 \\
Improvement of company image & 3.1 & 2.9 \\
Reason to certify according to ISO 14001 & & \\
$\quad$ Pressure from parent company & $3.0^{\mathrm{a}}$ & $2.0^{\mathrm{a}}$ \\
Pressure from customers & 2.3 & 2.3 \\
$\quad$ Pressure from government & 2.0 & 2.6 \\
Pressure from sector association & 2.0 & 1.7 \\
By own initiative & 3.6 & 3.5 \\
Added value of ISO 14001 certification & & \\
Without certification attention & 3.1 & 2.7 \\
$\quad$ will decrease & & \\
To show it to external parties & 3.6 & 3.3 \\
As a landmark and impulse for ourselves & $3.8^{\mathrm{a}}$ & $3.0^{\mathrm{a}}$ \\
Long-term financial benefit & 2.6 & 2.1 \\
\hline
\end{tabular}

${ }^{a}$ Significant according to Spearman's rank correlation test $(p<0.05)$.

\subsection{Other company aspects in relation to continual improvement}

Several other company aspects were compared for frontrunners and others. Some of them are worth mentioning here (see Table 6). There appears to be a positive relationship between continual improvement and voluntary agreements, companies' commitment to best available technology as long-term objective and environmental reporting.

Based on the results, yearly environmental reporting seems to act positive on continual improvement and companies which produce yearly environmental reports are more ambitious and have higher ambition levels. In addition, an effort is made to relate organizational types and general management strategies with continual improvement, but here we did not find clear and unambiguous results.

\subsection{Continual improvement over time}

As was argued above, a major way of realizing continual improvement is raising the ambition levels over time.

Table 6

Company aspects positively related with continual improvement

\begin{tabular}{lll}
\hline & $\begin{array}{l}\text { Front-runners } \\
\text { (out of 8) }\end{array}$ & $\begin{array}{l}\text { Companies } \\
\text { (out of 11) }\end{array}$ \\
\hline $\begin{array}{l}\text { Involvement in voluntary agreements } \\
\begin{array}{l}\text { Commitment to best available technology } \\
\text { as long-term objective (EVABAT as a } \\
\text { bottom line) }\end{array}\end{array}$ & $6(75 \%)$ & $5(45 \%)$ \\
Environmental reporting & $8(100 \%)$ & $6(55 \%)$ \\
\hline
\end{tabular}


Ambition is defined in stages from compliance, to full product life cycle management. We asked companies whether they had increased their ambition level in the past few years, and whether they expected to rise this level in the nearby years to come. Table 7 gives the four answer combinations.

Most of the front-runners (five of eight) are in the category of companies that stated that they had had an increase in ambition level in the near past, and expected to further improve in the near future. Only one of the front-runners does not expect to further improve in the future - this is a rather special case of a company oriented to product life cycle management for several years, with overall targets and objectives now set to a minimum by the parent company. The findings therefore hardly support the occurrence of a 'saturation effect' in continual improvement. Rather, the picture emerging is that of companies engaging in enduring improvement on one side, and companies stagnating - with no past improvement and no expected future improvement - on the other side.

\subsection{Sectoral differences}

There are some differences between the sectors investigated - chemical sector, food industry, and environmental services - but they scarcely affect the findings reported above. As far as our sample indicates, pressure of the parent company, from customers, and from government toward ISO 14001 certification is felt in the chemical sector somewhat harder than in the other two sectors.

On the other hand, the companies in the chemical sector hardly supported the motive that "without certification the attention for the EMS will decrease". With or without a certified ISO 14001 system, these companies systematically manage their environmental aspects.

The chemical companies investigated were also more ambitious, while the environmental services companies were less ambitious than average. The environmental services sector also scored lower on some other aspects, e.g. use of operational- and management performance indicators, improvement of ambition levels, commitment to best available technologies, and others. Nonetheless, front-runner companies were more or less equally divided over the sectors - three for chemical sector, three for food industries, and two for environmental services, therefore, some of these differences may result from the different nature of the company processes, rather than from differences in commitment to continual improvement.

Table 7

Ambition level improvement in the past and expected improvement in the future

\begin{tabular}{cclc}
\hline $\begin{array}{c}\text { Not improved, but } \\
\text { willing to improve }\end{array}$ & $4(21 \%)$ & $\begin{array}{l}\text { Improved and willing } \\
\text { to improve }\end{array}$ & $8(42 \%)$ \\
$\begin{array}{c}\text { Not improved, and not } \\
\text { able to improve }\end{array}$ & $6(32 \%)$ & $\begin{array}{l}\text { Improved, but not able } \\
\text { to improve }\end{array}$ & $1(5 \%)$ \\
\hline
\end{tabular}

\subsection{Certification bodies on measuring continual improvement}

According to the Dutch coordination body for certification of environmental management systems [19], certification bodies have to review continual improvement by investigating whether a company:

- has an understanding of its important environmental aspects;

- has an understanding of the options available for reducing pollution;

- has a plan in which the (non) application of the identified options in the future is explained;

- carries out the plans made.

Certification bodies do not evaluate the quality of environmental requirements contained in permits or in the organization's environmental programmes. According to ISO 14001 Certification, bodies should assess the compliance with legislative and other requirements, to which the company has committed. Permits should follow the legislative requirements, so it is not necessary to assess the quality of permits and other agreed arrangements, such as charters and codes of practice, themselves; only compliance with them has to be checked [9].

In line with these requirements, the certification bodies interviewed stated that they did not measure continual improvement as such. Companies have to measure continual improvement and demonstrate it to the certification body.

According to the respondents, in practice this means that certification bodies assess continual improvement in the following way:

- First, by looking at the company's risk assessment. Risk assessment, in this context, is an instrument to identify and assess the potential environmental impacts of an activity, product or service, evaluate alternatives, and design appropriate mitigation, management, and monitoring measures. Risk assessment is regarded as a starting point for continual improvement. The environmental aspects and impacts, derived from the risk assessment, are the base for the development of objectives.

- Second, by looking at the long- and short-term objectives. These objectives have to be formulated according to the abovementioned "SMART" principle. Organizations have to develop realistic objectives and targets that are measurable. By the next audit these objectives have to be realized, or at least dealt with.

- Third, by verifying that organizations are able to take, and, if needed, do take corrective actions, and preventive measures. Curative actions, and end of pipe technologies alone are not sufficient to qualify for continual improvement.

\section{Discussion and conclusions}

In this research a limited set of face-to-face interviews was selected rather than a larger mail survey. The results of these 
interviews, while not allowing for hard quantitative conclusions, provide an interesting and plausible view on the dynamics of continual improvement in ISO 14001.

First, they confirm that continual improvement, although it is crucial in ISO 14001, is a vague and ill-defined concept. The following, mutually related aspects require more clarity:

(a) Specifying minimal conditions to be met. It is unclear what constitutes the bottom line for continual improvement. We have argued that progress toward existing objectives which to date is often the central criterion - is not adequate as a bottom line.

(b) Differentiation between tactical and strategic improvement. We have argued that making a difference between these two levels of improvement - which can also be indicated as operational level and system level - is important in defining improvement. Particularly, the strategic or system level needs further elaboration in terms of operational-/process performance indicators and management-/ strategic performance indicators.

(c) Elaborating on the system boundaries. One major approach to strategic improvement is through the range of activities, focussing not only on internal processes, but also on issues of life cycle management, product stewardship, environment-oriented product development, and supplier requirements.

The results show, in accordance to the literature, that strategic improvement can vary widely under ISO 14001. Almost half of the interviewed companies are more or less standing still in terms of ambition levels. They have not raised, their ambition significantly over the last years, and do not expect to do so in the near future. This does not mean there is no improvement, but improvements go in small steps toward rather static objectives. In contrast, nearly half of the interviewed companies are consistently and significantly improving their performance, not only operationally but also in terms of environmental ambition levels.

Companies interviewed used a diversity of methods to monitor improvement. Most of these methods include measurements on operational level, as well as procedures for adjusting and raising the ambition levels of objectives. It would make little sense to suggest a uniform procedure here. On the basis of the results, however, some qualifying remarks can be made on assessing continual improvement within ISO 14001, such as using:

- a standard set of normalised indicators;

- a continual improvement report with a standardized content;

- standardized Plan-Do-Check-Act (PDCA) papers;

- different levels of improvement;

- a similar priority calculation.

Most of the companies (12), as well as three of the four certification bodies interviewed were not positive about comparing environmental action. It is very difficult to determine a uniform measure for continual improvement, as it is strongly dependent on organizational aspects, the location, the production process, and other company-specific factors. While companies and certifiers in majority rejected benchmarking between companies, we observed that companies which use more, different categories of indicators and which are frontrunners in continual improvement, tend to be more positive.

This may indicate that the more experience companies have, the more possibilities they see for benchmarking. It is useful, therefore, to further investigate these experiences and in particular to look for ways of using management performance indicators for better, quantitative assessment of improvement.

Concerning motivational factors, the findings clearly indicate that internal motivation - including the policy of the parent company - is a major driver of continual improvement. Front-runners in improvement use the certified EMS as a tool for directing the company's policy, and as a landmark, and impulse within the company. The soul of the machine, therefore, is formed by the internal drive of the company toward better performance, rather than the pressure of demonstrating performance externally. Our findings indicate a need for further research into this motivational base of continual improvement. They also suggest that in further elaboration of performance frameworks, it would be important not only to investigate ways of using indicators as external benchmarks, but also to explore the ways indicators can support the internal motivational processes of the company.

\section{References}

[1] Ammenberg J, Hjelm O. The connection between environmental management systems and continual environmental performance improvements. Corporate Environmental Strategy 2002;9(2):183-92.

[2] Bansal P, Bogner WC. Deciding on ISO 14001: economics, institutions, and context. Long Range Planning 2002;35:269-90.

[3] Brouwer M. Continue verbetering in ISO 14001: meten of vergeten? Wageningen: Wageningen University; 2004.

[4] Cochin TJ. Continuously improving your environmental strategies. Corporate Environmental Strategy 1998;5(2):57-60.

[5] Engel WE. Indicatoren voor milieuprestaties en hun evolutie in de context van een duurzame ontwikkeling; Tendensen in het gebruik en de normalisatie van indicatoren. Brussels: ABECE; 2001.

[6] Heida JF, Hortensius D, Fokke J, Stans J, de Vries H. Werken met ISO 14001. Delft: Nederlands Normalisatie-Instituut; 1997.

[7] Honkasalo A. The EMAS scheme: a management tool and instrument of environmental policy. The Journal of Cleaner Production 1998;6:119-28.

[8] Ilomäki M, Melanen M. Waste minimization in small and medium-sized enterprises - do environmental management systems help? The Journal of Cleaner Production 2001;9:209-17.

[9] International Organization for Standardization. ISO 14001:2004(E) environmental management systems - requirements with guidance for use. Geneva: ISO; 2004.

[10] International Organization for Standardization. ISO 14031: environmental management - environmental performance evaluation guidelines. Geneva: ISO; 1999.

[11] Jasch C. Environmental performance evaluation and indicators. The Journal of Cleaner Production 2000;8:79-88.

[12] van Koppen, Hagelaar JLF. Milieuzorg als strategische keuze. Bedrijfskunde 1998;1:45-51.

[13] Krut R, Gleckman H. ISO 14001, a missed opportunity for sustainable global industrial development. London: Earthscan; 1998. 
[14] McDonach K, Yaneske PP. Environmental management systems and sustainable development. The Environmentalist 2002;22:217-26.

[15] Moxen J, Strachan PA. ISO 14001: a case of cultural myopia. Eco-management and Auditing 2000;7:82-90.

[16] O'Reilly M, Wathey D, Gelber M. ISO 14031: effective mechanism to environmental performance evaluation. Corporate Environmental Strategy 2000;7(3):267-75.

[17] Peglau Reinhard. The Peglau liste, a list of worldwide ISO 14001 certificate numbers. Berlin: Federal Environmental Agency, $<$ http://www.14001 news.de $>$; 2005

[18] Rondinelli D, Vastag G. Panacea, common sense, or just a label? The value of ISO 14001 environmental management systems. European Management Journal 2000;18(5):499-510.

[19] Stichting Coördinatie Certificatie Milieuzorgsystemen. Certificatiesysteem milieuzorgsystemen volgens ISO 14001. Den Haag: SCCM; 2003.
[20] Veleva V, Ellenbecker M. Indicators of sustainable production: framework and methodology. The Journal of Cleaner Production 2002;9: 519-49.

[21] Zangwill WI, Kantor PB. Toward a theory of continuous improvement and the learning curve. Management Science 1998;44(7): 910-20.

Martin A.C. Brouwer graduated with an MSc Environmental Sciences from Wageningen University and is consultant in environmental management and technology at Cataly Partners B.V., The Netherlands.

C.S.A. (Kris) van Koppen is senior lecturer at the Environmental Policy Group of Wageningen University and professor in Environmental Education by special appointment at the University of Utrecht, The Netherlands. 